\title{
How Populations Cohere: Five Rules for Cooperation
}

Martin A. Nowak (nowak@fas.harvard.edu)

Karl Sigmund (karl.sigmund@univie.ac.at)

\section{Approved by}

Ulf Dieckmann

Leader, Evolution and Ecology Program

December 2007 Institute, its National Member Organizations, or other organizations supporting the work. 


\section{IIASA STUDIES IN ADAPTIVE DYNAMICS No. 136}

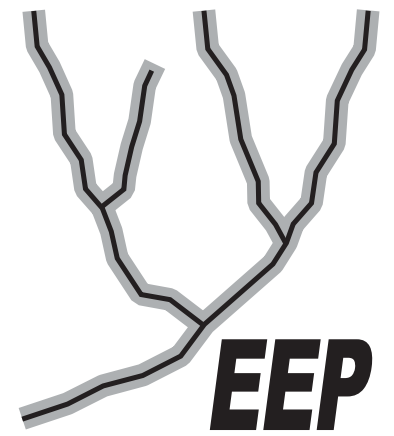

The Evolution and Ecology Program at IIASA fosters the development of new mathematical and conceptual techniques for understanding the evolution of complex adaptive systems.

Focusing on these long-term implications of adaptive processes in systems of limited growth, the Evolution and Ecology Program brings together scientists and institutions from around the world with IIASA acting as the central node.

Scientific progress within the network is collected in the IIASA Studies in Adaptive Dynamics series.
No. 1 Metz JAJ, Geritz SAH, Meszéna G, Jacobs FJA, van Heerwaarden JS: Adaptive Dynamics: A Geometrical Study of the Consequences of Nearly Faithful Reproduction. IIASA Working Paper WP-95-099 (1995). van Strien SJ, Verduyn Lunel SM (eds): Stochastic and Spatial Structures of Dynamical Systems, Proceedings of the Royal Dutch Academy of Science (KNAW Verhandelingen), North Holland, Amsterdam, pp. 183-231 (1996).

No. 2 Dieckmann U, Law R: The Dynamical Theory of Coevolution: A Derivation from Stochastic Ecological Processes. IIASA Working Paper WP-96-001 (1996). Journal of Mathematical Biology 34:579-612 (1996).

No. 3 Dieckmann U, Marrow P, Law R: Evolutionary Cycling of Predator-PreyInteractions: Population Dynamics and the Red Queen. IIASA Preprint (1995). Journal of Theoretical Biology 176:91-102 (1995).

No. 4 Marrow P, Dieckmann U, Law R: Evolutionary Dynamics of Predator-Prey Systems: An Ecological Perspective. IIASA Working Paper WP-96-002 (1996). Journal of Mathematical Biology 34:556-578 (1996).

No. 5 Law R, Marrow P, Dieckmann U: On Evolution under Asymmetric Competition. IIASA Working Paper WP-96-003 (1996). Evolutionary Ecology 11:485-501 (1997).

No. 6 Metz JAJ, Mylius SD, Diekmann O: When Does Evolution Optimize? On the Relation Between Types of Density Dependence and Evolutionarily Stable Life History Parameters. IIASA Working Paper WP-96-004 (1996).

No. 7 Ferrière R, Gatto M: Lyapunov Exponents and the Mathematics of Invasion in Oscillatory or Chaotic Populations. Theoretical Population Biology 48:126-171 (1995).

No. 8 Ferrière R, Fox GA: Chaos and Evolution. IIASA Preprint (1996). Trends in Ecology and Evolution 10:480485 (1995).

No. 9 Ferrière R, Michod RE: The Evolution of Cooperation in Spatially Heterogeneous Populations. IIASA Working Paper WP-96-029 (1996). The American Naturalist 147:692717 (1996).

No. 10 van Dooren TJM, Metz JAJ: Delayed Maturation in Temporally Structured Populations with Non-Equilibrium Dynamics. IIASA Working Paper WP-96-070 (1996). Journal of Evolutionary Biology 11:41-62 (1998).
No. 11 Geritz SAH, Metz JAJ, Kisdi É, Meszéna G: The Dynamics of Adaptation and Evolutionary Branching. IIASA Working Paper WP-96-077 (1996). Physical Review Letters 78:2024-2027 (1997).

No. 12 Geritz SAH, Kisdi É, Meszéna G, Metz JAJ: Evolutionary Singular Strategies and the Adaptive Growth and Branching of the Evolutionary Tree. IIASA Working Paper WP-96-114 (1996). Evolutionary Ecology 12:35-57 (1998).

No. 13 Heino M, Metz JAJ, Kaitala V: Evolution of Mixed Maturation Strategies in Semelparous Life-Histories: The Crucial Role of Dimensionality of Feedback Environment. IIASA Working Paper WP-96-126 (1996). Philosophical Transactions of the Royal Society of London Series B 352:1647-1655 (1997).

No. 14 Dieckmann U: Can Adaptive Dynamics Invade? IIASA Working Paper WP-96-152 (1996). Trends in Ecology and Evolution 12:128-131 (1997).

No. 15 Meszéna G, Czibula I, Geritz SAH: Adaptive Dynamics in a 2-Patch Environment: A Simple Model for Allopatric and Parapatric Speciation. IIASA Interim Report IR-97-001 (1997). Journal of Biological Systems 5:265-284 (1997).

No. 16 Heino M, Metz JAJ, Kaitala V: The Enigma of Frequency-Dependent Selection. IIASA Interim Report IR97-061 (1997). Trends in Ecology and Evolution 13:367-370 (1998).

No. 17 Heino M: Management of Evolving Fish Stocks. IIASA Interim Report IR-97-062 (1997). Canadian Journal of Fisheries and Aquatic Sciences 55:1971-1982 (1998).

No. 18 Heino M: Evolution of Mixed Reproductive Strategies in Simple Life-History Models. IIASA Interim Report IR-97063 (1997).

No. 19 Geritz SAH, van der Meijden E, Metz JAJ: Evolutionary Dynamics of Seed Size and Seedling Competitive Ability. IIASA Interim Report IR-97-071 (1997). Theoretical Population Biology 55:324-343 (1999).

No. 20 Galis F, Metz JAJ: Why Are There So Many Cichlid Species? On the Interplay of Speciation and Adaptive Radiation. IIASA Interim Report IR-97-072 (1997). Trends in Ecology and Evolution 13:1-2 (1998). 
No. 21 Boerlijst MC, Nowak MA, Sigmund K: Equal Pay for all Prisoners/ The Logic of Contrition. IIASA Interim Report IR-97-073 (1997). American Mathematical Society Monthly 104:303-307 (1997). Journal of Theoretical Biology 185:281-293 (1997).

No. 22 Law R, Dieckmann U: Symbiosis Without Mutualism and the Merger of Lineages in Evolution. IIASA Interim Report IR-97-074 (1997). Proceedings of the Royal Society of London Series B 265:1245-1253 (1998).

No. 23 Klinkhamer PGL, de Jong TJ, Metz JAJ: Sex and Size in Cosexual Plants. IIASA Interim Report IR-97-078 (1997). Trends in Ecology and Evolution 12:260-265 (1997).

No. 24 Fontana W, Schuster P: Shaping Space: The Possible and the Attainable in RNA Genotype-Phenotype Mapping. IIASA Interim Report IR-98-004 (1998). Journal of Theoretical Biology 194:491-515 (1998).

No. 25 Kisdi É, Geritz SAH: Adaptive Dynamics in Allele Space: Evolution of Genetic Polymorphism by Small Mutations in a Heterogeneous Environment. IIASA Interim Report IR-98-038 (1998). Evolution 53:993-1008 (1999).

No. 26 Fontana W, Schuster P: Continuity in Evolution: On the Nature of Transitions. IIASA Interim Report IR-98-039 (1998). Science 280:1451-1455 (1998).

No. 27 Nowak MA, Sigmund K: Evolution of Indirect Reciprocity by Image Scoring/ The Dynamics of Indirect Reciprocity. IIASA Interim Report IR-98-040 (1998). Nature 393:573-577 (1998). Journal of Theoretical Biology 194:561574 (1998).

No. 28 Kisdi É: Evolutionary Branching Under Asymmetric Competition. IIASA Interim Report IR-98-045 (1998). Journal of Theoretical Biology 197:149-162 (1999).

No. 29 Berger U: Best Response Adaptation for Role Games. IIASA Interim Report IR-98-086 (1998).

No. 30 van Dooren TJM: The Evolutionary Ecology of Dominance-Recessivity. IIASA Interim Report IR-98-096 (1998). Journal of Theoretical Biology 198:519-532 (1999).

No. 31 Dieckmann U, O'Hara B, Weisser W: The Evolutionary Ecology of Dispersal. IIASA Interim Report IR-98-108 (1998). Trends in Ecology and Evolution 14:88-90 (1999).

No. 32 Sigmund K: Complex Adaptive Systems and the Evolution of Reciprocation. IIASA Interim Report IR-98-100 (1998). Ecosystems 1:444-448 (1998).

No. 33 Posch M, Pichler A, Sigmund K: The Efficiency of Adapting Aspiration Levels. IIASA Interim Report IR-98103 (1998). Proceedings of the Royal Society London Series B 266:1427-1435 (1999).

No. 34 Mathias A, Kisdi É: Evolutionary Branching and Coexistence of Germination Strategies. IIASA Interim Report IR-99-014 (1999).

No. 35 Dieckmann U, Doebeli M: On the Origin of Species by Sympatric Speciation. IIASA Interim Report IR-99-013 (1999). Nature 400:354-357 (1999).

No. 36 Metz JAJ, Gyllenberg M: How Should We Define Fitness in Structured Metapopulation Models? Including an Application to the Calculation of Evolutionarily Stable Dispersal Strategies. IIASA Interim Report IR-99-019 (1999). Proceedings of the Royal Society of London Series B 268:499508 (2001)
No. 37 Gyllenberg M, Metz JAJ: On Fitness in Structured Metapopulations. IIASA Interim Report IR-99-037 (1999). Journal of Mathematical Biology 43:545-560 (2001).

No. 38 Meszéna G, Metz JAJ: Species Diversity and Population Regulation: The Importance of Environmental Feedback Dimensionality. IIASA Interim Report IR-99-045 (1999).

No. 39 Kisdi É, Geritz SAH: Evolutionary Branching and Sympatric Speciation in Diploid Populations. IIASA Interim Report IR-99-048 (1999).

No. 40 Ylikarjula J, Heino M, Dieckmann U: Ecology and Adaptation of Stunted Growth in Fish. IIASA Interim Report IR-99-050 (1999). Evolutionary Ecology 13:433-453 (1999).

No. 41 Nowak MA, Sigmund K: Games on Grids. IIASA Interim Report IR-99-038 (1999). Dieckmann U, Law R, Metz JAJ (eds): The Geometry of Ecological Interactions: Simplifying Spatial Complexity, Cambridge University Press, Cambridge, UK, pp. 135-150 (2000).

No. 42 Ferrière R, Michod RE: Wave Patterns in Spatial Games and the Evolution of Cooperation. IIASA Interim Report IR-99-041 (1999). Dieckmann U, Law R, Metz JAJ (eds): The Geometry of Ecological Interactions: Simplifying Spatial Complexity, Cambridge University Press, Cambridge, UK, pp. 318-332 (2000).

No. 43 Kisdi É, Jacobs FJA, Geritz SAH: Red Queen Evolution by Cycles of Evolutionary Branching and Extinction. IIASA Interim Report IR-00-030 (2000). Selection 2:161$176(2001)$.

No. 44 Meszéna G, Kisdi É, Dieckmann U, Geritz SAH, Metz JAJ: Evolutionary Optimisation Models and Matrix Games in the Unified Perspective of Adaptive Dynamics. IIASA Interim Report IR-00-039 (2000). Selection 2:193-210 (2001).

No. 45 Parvinen K, Dieckmann U, Gyllenberg M, Metz JAJ: Evolution of Dispersal in Metapopulations with Local Density Dependence and Demographic Stochasticity. IIASA Interim Report IR-00-035 (2000). Journal of Evolutionary Biology 16:143-153 (2003).

No. 46 Doebeli M, Dieckmann U: Evolutionary Branching and Sympatric Speciation Caused by Different Types of Ecological Interactions. IIASA Interim Report IR-00-040 (2000). The American Naturalist 156:S77-S101 (2000).

No. 47 Heino M, Hanski I: Evolution of Migration Rate in a Spatially Realistic Metapopulation Model. IIASA Interim Report IR-00-044 (2000). The American Naturalist 157:495$511(2001)$.

No. 48 Gyllenberg M, Parvinen K, Dieckmann U: Evolutionary Suicide and Evolution of Dispersal in Structured Metapopulations. IIASA Interim Report IR-00-056 (2000). Journal of Mathematical Biology 45:79-105 (2002).

No. 49 van Dooren TJM: The Evolutionary Dynamics of Direct Phenotypic Overdominance: Emergence Possible, Loss Probable. IIASA Interim Report IR-00-048 (2000). Evolution 54:1899-1914 (2000).

No. 50 Nowak MA, Page KM, Sigmund K: Fairness Versus Reason in the Ultimatum Game. IIASA Interim Report IR00-57 (2000). Science 289:1773-1775 (2000).

No. 51 de Feo O, Ferrière R: Bifurcation Analysis of Population Invasion: On-Off Intermittency and Basin Riddling. IIASA Interim Report IR-00-074 (2000). International Journal of Bifurcation and Chaos 10:443-452 (2000). 
No. 52 Heino M, Laaka-Lindberg S: Clonal Dynamics and Evolution of Dormancy in the Leafy Hepatic Lophozia Silvicola. IIASA Interim Report IR-01-018 (2001). Oikos 94:525-532 (2001).

No. 53 Sigmund K, Hauert C, Nowak MA: Reward and Punishment in Minigames. IIASA Interim Report IR-01-031 (2001). Proceedings of the National Academy of Sciences of the USA 98:10757-10762 (2001).

No. 54 Hauert C, De Monte S, Sigmund K, Hofbauer J: Oscillations in Optional Public Good Games. IIASA Interim Report IR-01-036 (2001).

No. 55 Ferrière R, Le Galliard J: Invasion Fitness and Adaptive Dynamics in Spatial Population Models. IIASA Interim Report IR-01-043 (2001). Clobert J, Dhondt A, Danchin E, Nichols J (eds): Dispersal, Oxford University Press, pp. 57-79 (2001).

No. 56 de Mazancourt C, Loreau M, Dieckmann U: Can the Evolution of Plant Defense Lead to Plant-Herbivore Mutualism? IIASA Interim Report IR-01-053 (2001). The American Naturalist 158:109-123 (2001).

No. 57 Claessen D, Dieckmann U: Ontogenetic Niche Shifts and Evolutionary Branching in Size-Structured Populations. IIASA Interim Report IR-01-056 (2001). Evolutionary Ecology Research 4:189-217 (2002).

No. 58 Brandt H: Correlation Analysis of Fitness Landscapes. IIASA Interim Report IR-01-058 (2001).

No. 59 Dieckmann U: Adaptive Dynamics of Pathogen-Host Interacations. IIASA Interim Report IR-02-007 (2002). Dieckmann U, Metz JAJ, Sabelis MW, Sigmund K (eds): Adaptive Dynamics of Infectious Diseases: In Pursuit of Virulence Management, Cambridge University Press, Cambridge, UK, pp. 39-59 (2002).

No. 60 Nowak MA, Sigmund K: Super- and Coinfection: The Two Extremes. IIASA Interim Report IR-02-008 (2002). Dieckmann U, Metz JAJ, Sabelis MW, Sigmund K (eds): Adaptive Dynamics of Infectious Diseases: In Pursuit of Virulence Management, Cambridge University Press, Cambridge, UK, pp. 124-137 (2002).

No. 61 Sabelis MW, Metz JAJ: Evolution Management: Taking Stock - Relating Theory to Experiment. IIASA Interim Report IR-02-009 (2002). Dieckmann U, Metz JAJ, Sabelis MW, Sigmund K (eds): Adaptive Dynamics of Infectious Diseases: In Pursuit of Virulence Management, Cambridge University Press, Cambridge, UK, pp. 379-398 (2002).

No. 62 Cheptou P, Dieckmann U: The Evolution of SelfFertilization in Density-Regulated Populations . IIASA Interim Report IR-02-024 (2002). Proceedings of the Royal Society of London Series B 269:1177-1186(2002).

No. 63 Bürger R: Additive Genetic Variation Under Intraspecific Competition and Stabilizing Selection: A Two-Locus Study. IIASA Interim Report IR-02-013 (2002). Theoretical Population Biology 61:197-213 (2002).

No. 64 Hauert C, De Monte S, Hofbauer J, Sigmund K: Volunteering as Red Queen Mechanism for Co-operation in Public Goods Games. IIASA Interim Report IR-02-041 (2002). Science 296:1129-1132 (2002).

No. 65 Dercole F, Ferrière R, Rinaldi S: Ecological Bistability and Evolutionary Reversals under Asymmetrical Competition. IIASA Interim Report IR-02-053 (2002). Evolution 56:1081-1090 (2002).
No. 66 Dercole F, Rinaldi S: Evolution of Cannibalistic Traits: Scenarios Derived from Adaptive Dynamics. IIASA Interim Report IR-02-054 (2002). Theoretical Population Biology 62:365-374 (2002).

No. 67 Bürger R, Gimelfarb A: Fluctuating Environments and the Role of Mutation in Maintaining Quantitative Genetic Variation. IIASA Interim Report IR-02-058 (2002). Genetical Research 80:31-46 (2002).

No. 68 Bürger R: On a Genetic Model of Intraspecific Competition and Stabilizing Selection. IIASA Interim Report IR02-062 (2002). Amer. Natur. 160:661-682 (2002).

No. 69 Doebeli M, Dieckmann U: Speciation Along Environmental Gradients. IIASA Interim Report IR-02-079 (2002). Nature 421:259-264 (2003).

No. 70 Dercole F, Irisson J, Rinaldi S: Bifurcation Analysis of a Prey-Predator Coevolution Model. IIASA Interim Report IR-02-078 (2002). SIAM Journal on Applied Mathematics 63:1378-1391 (2003).

No. 71 Le Galliard J, Ferrière R, Dieckmann U: The Adaptive Dynamics of Altruism in Spatially Heterogeneous Populations. IIASA Interim Report IR-03-006 (2003). Evolution 57:1-17 (2003).

No. 72 Taborsky B, Dieckmann U, Heino M: Unexpected Discontinuities in Life-History Evolution under SizeDependent Mortality. IIASA Interim Report IR-03-004 (2003). Proceedings of the Royal Society of London Series B 270:713-721 (2003).

No. 73 Gardmark A, Dieckmann U, Lundberg P: LifeHistory Evolution in Harvested Populations: The Role of Natural Predation. IIASA Interim Report IR-03-008 (2003). Evolutionary Ecology Research 5:239-257 (2003).

No. 74 Mizera F, Meszéna G: Spatial Niche Packing, Character Displacement and Adaptive Speciation Along an Environmental Gradient. IIASA Interim Report IR-03-062 (2003). Evolutionary Ecology Research 5:363-382 (2003).

No. 75 Dercole F: Remarks on Branching-Extinction Evolutionary Cycles. IIASA Interim Report IR-03-077 (2003). Journal of Mathematical Biology 47:569-580 (2003).

No. 76 Hofbauer J, Sigmund K: Evolutionary Game Dynamics. IIASA Interim Report IR-03-078 (2003). Bulletin of the American Mathematical Society 40:479-519 (2003).

No. 77 Ernande B, Dieckmann U, Heino M: Adaptive Changes in Harvested Populations: Plasticity and Evolution of Age and Size at Maturation. IIASA Interim Report IR03-058 (2003). Proceedings of the Royal Society of London Series B-Biological Sciences 271:415-423 (2004).

No. 78 Hanski I, Heino M: Metapopulation-Level Adaptation of Insect Host Plant Preference and Extinction-Colonization Dynamics in Heterogeneous Landscapes. IIASA Interim Report IR-03-028 (2003). Theoretical Population Biology 63:309-338 (2003).

No. 79 van Doorn G, Dieckmann U, Weissing FJ: Sympatric Speciation by Sexual Selection: A Critical Re-Evaluation. IIASA Interim Report IR-04-003 (2004). American Naturalist 163:709-725 (2004).

No. 80 Egas M, Dieckmann U, Sabelis MW: Evolution Restricts the Coexistence of Specialists and Generalists - the Role of Trade-off Structure. IIASA Interim Report IR-04-004 (2004). American Naturalist 163:518-531 (2004). 
No. 81 Ernande B, Dieckmann U: The Evolution of Phenotypic Plasticity in Spatially Structured Environments: Implications of Intraspecific Competition, Plasticity Costs, and Environmental Characteristics. IIASA Interim Report IR-04-006 (2004). Journal of Evolutionary Biology 17:613-628 (2004).

No. 82 Cressman R, Hofbauer J: Measure Dynamics on a One-Dimensional Continuous Trait Space: Theoretical Foundations for Adaptive Dynamics. IIASA Interim Report IR04-016 (2004).

No. 83 Cressman R: Dynamic Stability of the Replicator Equation with Continuous Strategy Space. IIASA Interim Report IR-04-017 (2004).

No. 84 Ravigné V, Olivieri I, Dieckmann U: Implications of Habitat Choice for Protected Polymorphisms. IIASA Interim Report IR-04-005 (2004). Evolutionary Ecology Research 6:125-145 (2004).

No. 85 Nowak MA, Sigmund K: Evolutionary Dynamics of Biological Games. IIASA Interim Report IR-04-013 (2004). Science 303:793-799 (2004).

No. 86 Vukics A, Asbóth J, Meszéna G: Speciation in Multidimensional Evolutionary Space. IIASA Interim Report IR-04-028 (2004). Physical Review 68:041-903 (2003).

No. 87 de Mazancourt C, Dieckmann U: Trade-off Geometries and Frequency-dependent Selection. IIASA Interim Report IR-04-039 (2004). American Naturalist 164:765-778 (2004).

No. 88 Cadet CR, Metz JAJ, Klinkhamer PGL: Size and the Not-So-Single Sex: Disentangling the Effects of Size on Sex Allocation. IIASA Interim Report IR-04-084 (2004). American Naturalist 164:779-792 (2004).

No. 89 Rueffler C, van Dooren TJM, Metz JAJ: Adaptive Walks on Changing Landscapes: Levins' Approach Extended. IIASA Interim Report IR-04-083 (2004). Theoretical Population Biology 65:165-178 (2004).

No. 90 de Mazancourt C, Loreau M, Dieckmann U: Understanding Mutualism When There is Adaptation to the Partner. IIASA Interim Report IR-05-016 (2005). Journal of Ecology 93:305-314 (2005).

No. 91 Dieckmann U, Doebeli M: Pluralism in Evolutionary Theory. IIASA Interim Report IR-05-017 (2005). Journal of Evolutionary Biology 18:1209-1213 (2005).

No. 92 Doebeli M, Dieckmann U, Metz JAJ, Tautz D: What We Have Also Learned: Adaptive Speciation is Theoretically Plausible. IIASA Interim Report IR-05-018 (2005). Evolution 59:691-695 (2005).

No. 93 Egas M, Sabelis MW, Dieckmann U: Evolution of Specialization and Ecological Character Displacement of Herbivores Along a Gradient of Plant Quality. IIASA Interim Report IR-05-019 (2005). Evolution 59:507-520 (2005).

No. 94 Le Galliard J, Ferrière R, Dieckmann U: Adaptive Evolution of Social Traits: Origin, Trajectories, and Correlations of Altruism and Mobility. IIASA Interim Report IR05-020 (2005). American Naturalist 165:206-224 (2005).

No. 95 Doebeli M, Dieckmann U: Adaptive Dynamics as a Mathematical Tool for Studying the Ecology of Speciation Processes. IIASA Interim Report IR-05-022 (2005). Journal of Evolutionary Biology 18:1194-1200 (2005).

No. 96 Brandt H, Sigmund K: The Logic of Reprobation: Assessment and Action Rules for Indirect Reciprocity. IIASA Interim Report IR-04-085 (2004). Journal of Theoretical Biology 231:475-486 (2004).
No. 97 Hauert C, Haiden N, Sigmund K: The Dynamics of Public Goods. IIASA Interim Report IR-04-086 (2004). Discrete and Continuous Dynamical Systems - Series B 4:575587 (2004).

No. 98 Meszéna G, Gyllenberg M, Jacobs FJA, Metz JAJ: Link Between Population Dynamics and Dynamics of Darwinian Evolution. IIASA Interim Report IR-05-026 (2005). Physical Review Letters 95:Article 078105 (2005).

No. 99 Meszéna G: Adaptive Dynamics: The Continuity Argument. IIASA Interim Report IR-05-032 (2005).

No. 100 Brännström NA, Dieckmann U: Evolutionary Dynamics of Altruism and Cheating Among Social Amoebas. IIASA Interim Report IR-05-039 (2005). Proceedings of the Royal Society London Series B 272:1609-1616 (2005).

No. 101 Meszéna G, Gyllenberg M, Pasztor L, Metz JAJ: Competitive Exclusion and Limiting Similarity: A Unified Theory. IIASA Interim Report IR-05-040 (2005).

No. 102 Szabo P, Meszéna G: Limiting Similarity Revisited. IIASA Interim Report IR-05-050 (2005).

No. 103 Krakauer DC, Sasaki A: The Greater than Two-Fold Cost of Integration for Retroviruses. IIASA Interim Report IR-05-069 (2005).

No. 104 Metz JAJ: Eight Personal Rules for Doing Science. IIASA Interim Report IR-05-073 (2005). Journal of Evolutionary Biology 18:1178-1181 (2005).

No. 105 Beltman JB, Metz JAJ: Speciation: More Likely Through a Genetic or Through a Learned Habitat Preference? IIASA Interim Report IR-05-072 (2005). Proceedings of the Royal Society of London Series B 272:1455-1463 (2005).

No. 106 Durinx M, Metz JAJ: Multi-type Branching Processes and Adaptive Dynamics of Structured Populations. IIASA Interim Report IR-05-074 (2005). Haccou P, Jager P, Vatutin V (eds): Branching Processes: Variation, Growth and Extinction of Populations, Cambridge University Press, Cambridge, UK, pp. 266-278 (2005).

No. 107 Brandt H, Sigmund K: The Good, the Bad and the Discriminator - Errors in Direct and Indirect Reciprocity. IIASA Interim Report IR-05-070 (2005). Journal of Theoretical Biology 239:183-194 (2006).

No. 108 Brandt H, Hauert C, Sigmund K: Punishing and Abstaining for Public Goods. IIASA Interim Report IR-05-071 (2005). Proceedings of the National Academy of Sciences of the United States of America 103:495-497 (2006).

No. 109 Ohtsuki A, Sasaki A: Epidemiology and DiseaseControl Under Gene-for-Gene Plant-Pathogen Interaction. IIASA Interim Report IR-05-068 (2005).

No. 110 Brandt H, Sigmund K: Indirect Reciprocity, ImageScoring, and Moral Hazard. IIASA Interim Report IR-05078 (2005). Proceedings of the National Academy of Sciences of the United States of America 102:2666-2670 (2005).

No. 111 Nowak MA, Sigmund K: Evolution of Indirect Reciprocity. IIASA Interim Report IR-05-079 (2005). Nature 437:1292-1298 (2005).

No. 112 Kamo M, Sasaki A: Evolution Towards Multi-Year Periodicity in Epidemics. IIASA Interim Report IR-05-080 (2005). Ecology Letters 8:378-385 (2005). 
No. 113 Dercole F, Ferrière R, Gragnani A, Rinaldi S: Coevolution of Slow-fast Populations: Evolutionary Sliding, Evolutionoary Pseudo-equilibria, and Complex Red Queen Dynamics. IIASA Interim Report IR-06-006 (2006). Proceedings of the Royal Society B 273:983-990 (2006).

No. 114 Dercole F: Border Collision Bifurcations in the Evolution of Mutualistic Interactions. IIASA Interim Report IR-05-083 (2005). International Journal of Bifurcation and Chaos 15:2179-2190 (2005).

No. 115 Dieckmann U, Heino M, Parvinen K: The Adaptive Dynamics of Function-Valued Traits. IIASA Interim Report IR-06-036 (2006). Journal of Theoretical Biology 241:370389 (2006).

No. 116 Dieckmann U, Metz JAJ: Surprising Evolutionary Predictions from Enhanced Ecological Realism. IIASA Interim Report IR-06-037 (2006). Theoretical Population Biology 69:263-281 (2006).

No. 117 Dieckmann U, Brännström NA, HilleRisLambers R, Ito H: The Adaptive Dynamics of Community Structure. IIASA Interim Report IR-06-038 (2006). Takeuchi Y, Iwasa Y, Sato K (eds): Mathematics for Ecology and Environmental Sciences, Springer, Berlin Heidelberg, pp. 145-177 (2007).

No. 118 Gardmark A, Dieckmann U: Disparate Maturation Adaptations to Size-dependent Mortality. IIASA Interim Report IR-06-039 (2006). Proceedings of the Royal Society London Series B 273:2185-2192 (2006).

No. 119 van Doorn G, Dieckmann U: The Long-term Evolution of Multi-locus Traits Under Frequency-dependent Disruptive Selection. IIASA Interim Report IR-06-041 (2006). Evolution 60:2226-2238 (2006).

No. 120 Doebeli M, Blok HJ, Leimar O, Dieckmann U: Multimodal Pattern Formation in Phenotype Distributions of Sexual Populations. IIASA Interim Report IR-06-046 (2006). Proceedings of the Royal Society London Series B 274:347357 (2007).

No. 121 Dunlop ES, Shuter BJ, Dieckmann U: The Demographic and Evolutionary Consequences of Selective Mortality: Predictions from an Eco-genetic Model of the Smallmouth Bass. IIASA Interim Report IR-06-060 (2006). Transactions of the American Fisheries Society 136:749-765 (2007).

No. 122 Metz JAJ: Fitness. IIASA Interim Report IR-06061 (2006)

No. 123 Brandt H, Ohtsuki H, Iwasa Y, Sigmund K: A Survey on Indirect Reciprocity. IIASA Interim Report IR-06-065 (2006). Takeuchi Y, Iwasa Y, Sato K (eds): Mathematics for Ecology and Environmental Sciences, Springer, Berlin Heidelberg, pp. 21-51 (2007).
No. 124 Dercole F, Loiacono D, Rinaldi S: Synchronization in Ecological Networks: A Byproduct of Darwinian Evolution? IIASA Interim Report IR-06-068 (2006). International Journal of Bifurcation and Chaos 7:2435-2446 (2007).

No. 125 Dercole F, Dieckmann U, Obersteiner M, Rinaldi S: Adaptive Dynamics and Technological Change. IIASA Interim Report IR-06-070 (2006).

No. 126 Rueffler C, van Dooren TJM, Metz JAJ: The Evolution of Resource Specialization Through FrequencyDependent and Frequency-Independent Mechanisms. IIASA Interim Report IR-06-073 (2006). American Naturalist 167:81-93 (2006).

No. 127 Rueffler C, Egas M, Metz JAJ: Evolutionary Predictions Should be Based on Individual Traits. IIASA Interim Report IR-06-074 (2006). American Naturalist 168:148-162 (2006).

No. 128 Kamo M, Sasaki A, Boots M: The Role of Trade-Off Shapes in the Evolution of Virulence in Spatial Host-Parasite Interactions: An Approximate Analytical Approach . IIASA Interim Report IR-06-075 (2006).

No. 129 Boots M, Kamo M, Sasaki A: The Implications of Spatial Structure Within Populations to the Evolution of Parasites. IIASA Interim Report IR-06-078 (2006).

No. 130 Andreasen V, Sasaki A: Shaping the Phylogenetic Tree of Influenza by Cross-Immunity. IIASA Interim Report IR-06-079 (2006).

No. 131 Rueffler C, van Dooren TJM, Metz JAJ: The Interplay Between Behavior and Morphology in the Evolutionary Dynamics of Resource Specialization. IIASA Interim Report IR-06-082 (2006). American Naturalist 169:E34-E52 (2007).

No. 132 Rueffler C, van Dooren TJM, Metz JAJ: The Evolution of Simple Life-Histories: Steps Towards a Classification. IIASA Interim Report IR-06-083 (2006).

No. 133 Durinx M, Metz JAJ, Meszéna G: Adaptive Dynamics for Physiologically Structured Population Models. IIASA Interim Report IR-07-027 (2007).

No. 134 Ito H, Dieckmann U: A New Mechanism for Recurrent Adaptive Radiations. IIASA Interim Report IR-07-048 (2007). American Naturalist 170:E96-E111 (2007).

No. 135 Troost T, Kooi B, Dieckmann U: Joint evolution of predator body size and prey-size preference. IIASA Interim Report IR-07-050 (2007).

No. 136 Nowak MA, Sigmund K: How populations cohere: Five rules for cooperation. IIASA Interim Report IR-07-052 (2007). May RM, McLean A (eds): Theoretical Ecology: Principles and Applications, Oxford UP, Oxford, pp. 7-16 (2007).

Issues of the IIASA Studies in Adaptive Dynamics series can be obtained at www.iiasa.ac.at/Research/EEP/Series.html or by writing to eep@iiasa.ac.at. 


\section{Contents}

Abstract.1.1. 


\title{
How populations cohere: five rules for cooperation
}

\author{
Martin A. Nowak ${ }^{a}$, Karl Sigmund ${ }^{b, c}$ \\ ${ }^{a}$ The Program of Evolutionary Dynamics, Faculty of Arts and Science, One Brattle \\ Square, Harvard University, Cambridge, MA02138, USA. E-mail: \\ nowak@fas.harvard.edu \\ ${ }^{b}$ Faculty of Mathematics, University of Vienna, Nordbergstrasse 15, A-1090 Vienna, \\ Austria.E-mail: karl.sigmund@univie.ac.at \\ ${ }^{c}$ Evolution and Ecology Program, International Institute for Applied Systems Analysis, \\ Schlossplatz 1, A-2361 Laxenburg, Austria.Email: sigmund@iiasa.ac.at
}

Subsequent chapters in this volume ${ }^{1}$ deal with populations as dynamic entities in time and space. Populations are, of course, made up of individuals, and the parameters which characterize aggregate behavior-population growth rate and so on-ultimately derive from the behavioral ecology and life-history strategies of these constituent individuals. In evolutionary terms, the properties of populations can only be understood in terms of individuals, which comes down to studying how life-history choices (and consequent gene-frequency distributions) are shaped by environmental forces.

Many important aspects of group behavior-from alarm calls of birds and mammals to the complex institutions that have enabled human societies to flourish-pose problems of how cooperative behavior can evolve and be maintained. The puzzle was emphasized by Darwin, and remains the subject of active research today.

In this book, we leave the large subject of individual organisms' behavioral ecology and life-history choices to texts in that field (e.g. Krebs and Davies, 1997). Instead, we lead with a survey of work, much of it very recent, on five different kinds of mechanism whereby cooperative behavior may be maintained in a population, despite the inherent difficulty that cheats may prosper by enjoying the benefits of cooperation without paying the associated costs.

Cooperation means that a donor pays a cost, c, for a recipient to get a benefit, b. In evolutionary biology, cost and benefit are measured in terms of fitness. While mutation and selection represent the main forces of evolutionary dynamics, cooperation is a fundamental principle that is required for every level of biological organization. Individual cells rely on cooperation among their components. Multicellular organisms exist because of cooperation among their cells. Social insects are masters of cooperation. Most aspects of human society are based on mechanisms that promote cooperation. Whenever evolution constructs something entirely new (such as multicellularity or human language), cooperation is needed. Evolutionary construction is based on cooperation.

\footnotetext{
${ }^{1}$ This paper will be published as book chapter in R M May and A McLean (eds) Theoretical Ecology: Principles and Applications, Oxford UP, Oxford (2007).
} 
The five rules for cooperation which we examine in this chapter are: kin selection, direct reciprocity, indirect reciprocity, graph selection, and group selection. Each of these can promote cooperation if specific conditions are fulfilled.

\subsection{Kin selection}

The heated conversation took place in an unheated British pub over some pints of warm bitter. Suddenly J.B.S. Haldane remarked, 'I will jump into the river to save two brothers or eight cousins.' The founding father of population genetics and dedicated communist in his spare time never bothered to write up this insight. The witness of the revelation was Haldane's eager pupil, the young John Maynard Smith. But given John's high regard for entertaining stories and good beer, can we trust his memory?

The insight that Haldane might have had in the pub was precisely formulated by William Hamilton. He wrote a PhD thesis on this topic, submitted a long paper to the Journal of Theoretical Biology, and spent much of the next decade in the Brazilian jungle. This was arguably the most important paper in evolutionary biology in the second half of the twentieth century (Hamilton, 1964a, 1964b, 1998). The theory was termed kin selection by Maynard Smith (1964). The crucial equation is the following. Cooperation among relatives can be favored by natural selection if the coefficient of genetic relatedness, $r$, between the donor and the recipient exceeds the cost/benefit ratio of the altruistic act:

$r>c / b$

Kin-selection theory has been tested in numerous experimental studies. Indeed, many cooperative acts among animals occur between close kin (Frank, 1998; Hamilton, 1998). The exact relationship between kin selection and other mechanisms such as group selection and spatial reciprocity, however, remains unclear. A recent study even suggests that much of cooperation in social insects is due to group selection rather than kin selection (Wilson and Hölldobler, 2005). Note that kin selection is more likely to work in quite small groups; in large groups, unless highly inbred, the average value of $r$ will be tiny.

\subsection{Direct reciprocity}

In 1971, Robert Trivers published a landmark paper entitled 'The evolution of reciprocal altruism' (Trivers, 1971). Trivers analyzed the question how natural selection could lead to cooperation between unrelated individuals. He discusses three biological examples: cleaning symbiosis in fish, warning calls in birds, and human interactions. Trivers cites Luce and Raiffa (1957) and Rapoport and Chammah (1965) for the Prisoner's Dilemma, which is a game where two players have the option to cooperate or to defect. If both cooperate they receive the reward, $R$. If both defect they receive the punishment, $P$. If one cooperates and the other defects, then the cooperator receives the sucker's payoff, $S$, while the defector receives the temptation, $T$. The Prisoner's Dilemma is defined by the ranking $T>R>P>S$. 
Would you cooperate or defect? Assuming the other person will cooperate it is better to defect, because $T>R$. Assuming the other person will defect it is also better to defect, because $P>S$. Hence, no matter what the other person will do it is best to defect. If both players analyze the game in this rational way then they will end up defecting. The dilemma is that they both could have received a higher payoff if they had chosen to cooperate. But cooperation is irrational.

We can also imagine a population of cooperators and defectors and assume that the payoff for each player is determined by many random interactions with others. Let $x$ denote the frequency of cooperators and $1-x$ the frequency of defectors. The expected payoff for a cooperator is $f_{C}=R x+S(1-x)$. The expected payoff for a defector is $f_{D}=T x+P(1-x)$. Therefore, for any $x$, defectors have a higher payoff than cooperators. In evolutionary game theory, payoff is interpreted as fitness. Successful strategies reproduce faster and outcompete less successful ones. Reproduction can be cultural or genetic. In the non-repeated Prisoner's Dilemma, in a well-mixed population, defectors will outcompete cooperators. Natural selection favors defectors.

Cooperation becomes an option if the game is repeated. Suppose there are $m$ rounds. Let us compare two strategies, always defect (ALLD), and GRIM, which cooperates on the first move, then cooperates as long as the opponent cooperates, but permanently switches to defection if the opponent defects once. The expected payoff for GRIM versus GRIM is $n R$. The expected payoff for ALLD versus GRIM is $T+(m-1) P$. If $n R>T+(m-1) P$ then ALLD cannot spread in a GRIM population when rare. This is an argument of evolutionary stability. Interestingly, Trivers (1971) quotes 'Hamilton (pers. commun.)' for this idea.

A small problem with the above analysis is that given a known number of rounds it is best to defect in the last round and by backwards induction it is also best to defect in the penultimate round and so on. Therefore, it is more natural to consider a repeated game with a probability $w$ of having another round. In this case, the expected number of rounds is $1 /(1-w)$, and GRIM is stable against invasion by ALLD provided $w>(T-R) /(T-P)$.

We can also formulate the Prisoner's Dilemma as follows. The cooperator helps at a cost, $c$, and the other individual receives a benefit, $b$. Defectors do not help. Therefore we have $T=b, R=b-c, P=0$, and $S=-c$. The family of games that is described by the parameters $b$ and $c$ is a subset of all possible Prisoner's Dilemma games as long as $b>c$. For the repeated Prisoner's Dilemma, we find that ALLD cannot invade GRIM if

$w>c / b$

The probability of having another round must exceed the cost/benefit ratio of the altruistic act (Axelrod and Hamilton, 1981; Axelrod, 1984). Notice, however, the implicit assumption here that the payoff for future rounds is not discounted (i.e. distant benefits count as much as present ones). In evolutionary reality, this is unlikely. We can address this by incorporating an appropriate discount factor in $w$ (May, 1987), but note, from eqn 2 , that this makes cooperation less likely. 
Thus, the repeated Prisoner's Dilemma allows cooperation, but the question arises: what is a good strategy for playing this game? This question was posed by the political scientist, Robert Axelrod. In 1979, he decided to conduct a tournament of computer programs playing the repeated Prisoner's Dilemma. He received 14 entries, of which the surprise winner was tit-for-tat (TFT), the simplest of all strategies that were submitted. TFT cooperates in the first move, and then does whatever the opponent did in the previous round. TFT cooperates if you cooperate, TFT defects if you defect. It was submitted by the game theorist Anatol Rapoport (who is also the co-author of the book Prisoner's Dilemma; Rapoport and Chammah, 1965). Axelrod analyzed the events of the tournament, published a detailed account and invited people to submit strategies for a second championship. This time he received 63 entries. John Maynard Smith submitted tit-for-two-tats, a variant of TFT which defects only after the opponent has defected twice in a row. Only one person, Rapoport, submitted TFT, and it won again. At this time, TFT was considered to be the undisputed world champion in the heroic world of the repeated Prisoner's Dilemma.

But one weakness became apparent very soon (Molander, 1985). TFT cannot correct mistakes. The tournaments were conducted without strategic noise. In a real world, trembling hands and fuzzy minds cause erroneous moves. If two TFT players interact with each other, a single mistake leads to a long sequence of alternating defection and cooperation. In the long run two TFT players get the same low payoff as two players who flip coins for every move in order to decide whether to cooperate or to defect. Errors destroy TFT.

Our own investigations in this area began after reading a News and Views article in Nature where the author made three important points: first, he often leaves university meetings with a renewed appreciation for the problem of how natural selection can favor cooperative acts given that selfish individuals gain from cheating; second, strategies in the repeated Prisoner's Dilemma should not be error-free but subjected to noise; third, evolutionary stability should be tested not against single invaders but against heterogeneous ensembles of invaders (May, 1987). This was the motivation for the following work.

In 1989, we conducted evolutionary tournaments. Instead of inviting experts to submit programs, we asked mutation and selection to explore (some portion of) the strategy space of the repeated Prisoner's Dilemma in the presence of noise. The initial random ensemble of strategies was quickly dominated by ALLD. If the opposition is random, it is best to defect. A large portion of the population began to adopt the ALLD strategy and everything seemed lost. But after some time, a small cluster of players adopted a strategy very close to TFT. If this cluster is sufficiently large, then it can increase in abundance, and the entire population swings from ALLD to TFT. Reciprocity (and therefore cooperation) has emerged. We can show that TFT is the best catalyst for the emergence of cooperation. But TFT's moment of glory was brief and fleeting. In all cases, TFT was rapidly replaced by another strategy. On close inspection, this strategy turned out to be generous tit-for-tat (GTFT), which always cooperates if the opponent has cooperated on the previous move, but sometimes (probabilistically) even cooperates 
when the opponent has defected. Natural selection had discovered forgiveness (Nowak and Sigmund, 1992).

After many generations, however, GTFT is undermined by unconditional cooperators, ALLC. In a society where everybody is nice (using GTFT), there is almost no need to remember how to retaliate against a defection. A biological trait that is not used is likely to be lost by random drift. Birds that escape to islands without predators lose the ability to fly. Similarly, a GTFT population is softened and turns into an ALLC population.

Once most people play ALLC, there is an open invitation for ALLD to seize power. This is precisely what happens. The evolutionary dynamics run in cycles: from ALLD to TFT to GTFT to ALLC and back to ALLD. These oscillations of cooperative and defective societies are a fundamental part of all our observations regarding the evolution of cooperation. Most models of cooperation show such oscillations. Cooperation is never a final state of evolutionary dynamics. Instead it is always lost to defection after some time and has to be re-established. These oscillations are also reminiscent of alternating episodes of war and peace in human history (Figure 2.1).

A subsequent set of simulations, exploring a larger strategy space, led to a surprise (Nowak and Sigmund, 1993). The fundamental oscillations were interrupted by another strategy which seems to be able to hold its ground for a very long period of time. Most surprisingly, this strategy is based on the extremely simple principle of win-stay, loseshift (WSLS). If my payoff is $\mathrm{R}$ or $\mathrm{T}$ then I will continue with the same move next round. If I have cooperated then I will cooperate again, if I have defected then I will defect again. If my payoff is only $S$ or $P$ then I will switch to the other move next round. If I have cooperated then I will defect, if I have defected then I will cooperate (Figure 2.2).

If two WSLS strategists play each other, they cooperate most of the time. If a defection occurs accidentally, then in the next move both will defect. Hereafter both will cooperate again. WSLS is a simple deterministic machine to correct stochastic noise. While TFT cannot correct mistakes, both GTFT and WSLS can. But WSLS has an additional ace in its hand. When WSLS plays ALLC it will discover after some time that ALLC does not retaliate. After an accidental defection, WSLS will switch to permanent defection. Therefore, a population of WSLS players does not drift to ALLC. Cooperation based on WSLS is more stable than cooperation based on TFT-like strategies.

The repeated Prisoner's Dilemma is mostly known as a story of TFT, but WSLS is a superior strategy in an evolutionary scenario with errors, mutation, and many generations (Fudenberg and Maskin, 1990; Nowak and Sigmund, 1993).

In the infinitely repeated game, WSLS is stable against invasion by ALLD if $b / c>2$. If instead $1<b / c<2$ then a stochastic variant of WSLS dominates the scene; this strategy cooperates after a mutual defection only with a certain probability. Of course, all strategies of direct reciprocity, such as TFT, GTFT, or WSLS can only lead to the evolution of cooperation if the fundamental inequality (eqn 2) is fulfilled. 


\subsection{Indirect reciprocity}

Whereas direct reciprocity embodies the idea of you scratch my back and I scratch yours, indirect reciprocity suggests that you scratch my back and I scratch someone else's. Why should this work? Presumably I will not get scratched if it becomes known that I scratch nobody. Indirect reciprocity, in this view, is based on reputation (Nowak and Sigmund, 1998a, 1998b, 2005). But why should you care about what I do to a third person?

The main reason why economists and social scientists are interested in indirect reciprocity is because one-shot interactions between anonymous partners in a global market become increasingly frequent and tend to replace the traditional long-lasting associations and long-term interactions between relatives, neighbors, or members of the same village. Again, as for kin selection, it is a question of the size of the group. A substantial part of our life is spent in the company of strangers, and many transactions are no longer face to face. The growth of online auctions and other forms of e-commerce is based, to a considerable degree, on reputation and trust. The possibility to exploit such trust raises what economists call moral hazards. How effective is reputation, especially if information is only partial?

Evolutionary biologists, on the other hand, are interested in the emergence of human societies, which constitutes the last (up to now) of the major transitions in evolution. In contrast to other eusocial species, such as bees, ants, or termites, humans display a large amount of cooperation between non-relatives (Fehr and Fischbacher, 2003). A considerable part of human cooperation is based on moralistic emotions, such as anger directed towards cheaters or the warm inner glow felt after performing an altruistic action. Intriguingly, humans not only feel strongly about interactions that involve them directly, they also judge actions between third parties as evidenced by the contents of gossip. There are numerous experimental studies of indirect reciprocity based on reputation (Wedekind and Milinski, 2000; Milinski et al., 2002; Wedekind and Braithwaite, 2002; Seinen and Schram, 2006).

A simple model of indirect reciprocity (Nowak and Sigmund, 1998a, 1998b) assumes that within a well-mixed population, individuals meet randomly, one in the role of the potential donor, the other as potential recipient. Each individual experiences several rounds of this interaction in both roles, but never with the same partner twice. A player can follow either an unconditional strategy, such as always cooperate or always defect, or a conditional strategy, which discriminates among the potential recipients according to their past interactions. In a simple example, a discriminating donor helps a recipient if her score exceeds a certain threshold. A player's score is 0 at birth, increases whenever that player helps and decreases whenever the player withholds help. Individualbased simulations and direct calculations show that cooperation based on indirect reciprocity can evolve provided the probability, $p$, of knowing the social score of another person exceeds the cost/benefit ratio of the altruistic act:

$p>c / b$ 
The role of genetic relatedness that is crucial for kin selection is replaced by social acquaintanceship. In a fluid population, where most interactions are anonymous and people have no possibility of monitoring the social score of others, indirect reciprocity has no chance. But in a socially viscous population, where people know each other's reputation, cooperation by indirect reciprocity can thrive (Nowak and Sigmund, 1998a).

In a world of binary moral judgements (Nowak and Sigmund, 1998b; Leimar and Hammerstein, 2001; Fishman, 2003; Panchanathan and Boyd, 2003; Brandt and Sigmund, 2004, 2005), there are four ways of assessing donors in terms of first-order assessment: always consider them as good, always consider them as bad, consider them as good if they refuse to give, or consider them as good if they give. Only this last option makes sense. Second-order assessment also depends on the score of the receiver; for example, it can be deemed good to refuse help to a bad person. There are 16 second-order rules. Third-order assessment also depends on the score of the donor; for example, a good person refusing to help a bad person may remain good, but a bad person refusing to help a bad person remains bad. There are 256 third-order assessment rules. We display four of them in Figure 2.3.

With the scoring assessment rule, cooperation, C, always leads to a good reputation, G, whereas defection, D, always leads to a bad reputation, B. Standing (Sugden, 1986) is like scoring, but it is not bad if a good donor defects against a bad recipient. With judging, in addition, it is bad to cooperate with a bad recipient. For another assessment rule, shunning, all donors who meet a bad recipient become bad, regardless of what action they choose. Shunning strikes us as grossly unfair, but it emerges as the winner in a computer tournament if errors in perception are included and if there are only a few rounds in the game (Takahashi and Mashima, 2003).

An action rule for indirect reciprocity prescribes giving or not giving, depending on the scores of both donor and recipient. For example, you may decide to help if the recipient's score is good or your own score is bad. Such an action might increase your own score and therefore increase the chance of receiving help in the future. There are 16 action rules.

If we view a strategy as the combination of an action rule and an assessment rule, we obtain 4096 strategies. In a remarkable calculation, Ohtsuki and Iwasa (2004, 2005) analyzed all 4096 strategies and proved that only eight of them are evolutionarily stable under certain conditions and lead to cooperation (Figure 2.4).

Both standing and judging belong to the leading eight, but scoring and shunning are not. However, we expect that scoring has a similar role in indirect reciprocity to that of TFT in direct reciprocity. Neither strategy is evolutionarily stable, but their simplicity and their ability to catalyze cooperation in adverse situations constitute their strength. In extended versions of indirect reciprocity, in which donors can sometimes deceive others about the reputation of the recipient, scoring is the foolproof concept of 'I believe what I see'. Scoring judges the action and ignores the stories. There is also experimental evidence that in certain situations humans follow scoring rather than standing (Milinski et al., 2001). 
In human evolution, there must have been a tendency to move from the simple cooperation promoted by kin or group selection to the strategic subtleties of direct and indirect reciprocity. Direct reciprocity requires precise recognition of individual people, a memory of the various interactions one had with them in the past, and enough brain power to conduct multiple repeated games simultaneously. Indirect reciprocity, in addition, requires the individual to monitor interactions among other people, possibly judge the intentions that occur in such interactions, and keep up with the ever-changing social network of the group. Reputation of players may not only be determined by their own actions, but also by their associations with others.

We expect that indirect reciprocity has coevolved with human language. On the one hand, it is helpful to have names for other people and to receive information about how a person is perceived by others. On the other hand a complex language is needed, especially if there are intricate social interactions. The possibilities for games of manipulation, deceit, cooperation, and defection are limitless. It is likely that indirect reciprocity has provided the very selective scenario that led to cerebral expansion in human evolution.

\subsection{Graph selection}

The traditional model of evolutionary game dynamics assumes that populations are wellmixed (Taylor and Jonker, 1978; Hofbauer and Sigmund, 1998). This means that interactions between any two players are equally likely. More realistically, however, the interactions between individuals are governed by spatial effects or social networks. Let us therefore assume that the individuals of a population occupy the vertices of a graph (Nakamaru et al., 1997, 1998; Skyrms and Pemantle, 2000; Abramson and Kuperman, 2001; Ebel and Bornholdt, 2002; Lieberman et al., 2005; Nakamaru and Iwasa, 2005; Santos et al., 2005; Santos and Pacheco, 2005). The edges of the graph determine who interacts with whom (Figure 2.5).

Consider a population of $N$ individuals consisting of cooperators and defectors. A cooperator helps all individuals to whom it is connected, and pays a cost, $c$. If a cooperator is connected to $k$ other individuals and $i$ of those are cooperators, then its payoff is $b i-c k$. A defector does not provide any help, and therefore has no costs, but it can receive the benefit from neighboring cooperators. If a defector is connected to $k$ other individuals and $j$ of those are cooperators, then its payoff is $b j$. Evolutionary dynamics are described by an extremely simple stochastic process: at each time step, a random individual adopts the strategy of one of its neighbors proportional to their fitness.

We note that stochastic evolutionary game dynamics in finite populations is sensitive to the intensity of selection. In general, the reproductive success (fitness) of an individual is given by a constant, denoting the baseline fitness, plus the payoff that arises from the game under consideration. Strong selection means that the payoff is large compared with the baseline fitness; weak selection means the payoff is small compared with the baseline fitness. It turns out that many interesting results can be proven for weak selection, which is an observation also well known in population genetics. 
The traditional, well-mixed population of evolutionary game theory is represented by the complete graph, where all vertices are connected, which means that all individuals interact equally often. In this special situation, cooperators are always opposed by natural selection. This is the fundamental intuition of classical evolutionary game theory. But what happens on other graphs?

We need to calculate the probability, $\rho_{C}$, that a single cooperator starting in a random position turns the whole population from defectors into cooperators. If selection neither favors nor opposes cooperation, then this probability is $1 / N$, which is the fixation probability of a neutral mutant. If the fixation probability $\rho_{C}$ is greater than $1 / N$, then selection favors the emergence of cooperation. Similarly, we can calculate the fixation probability of defectors, $\rho_{D}$. A surprisingly simple rule determines whether selection on graphs favors cooperation. If

$b / c>k$

then cooperators have a fixation probability of greater than $1 / N$ and defectors have a fixation probability of less than $1 / N$. Thus, for graph selection to favor cooperation, the benefit/cost ratio of the altruistic act must exceed the average degree, $k$, which is given by the average number of links per individual (Ohtsuki et al., 2006). This relationship can be shown with the method of pair-approximation for regular graphs, where all individuals have exactly the same number of neighbors. Regular graphs include cycles, all kinds of spatial lattice, and random regular graphs. Moreover, computer simulations suggest that the rule $b / c>k$ also holds for non-regular graphs such as random graphs and scale-free networks. The rule holds in the limit of weak selection and $k \ll N$. For the complete graph, $k=N$, we always have $\rho_{D}>1 / N>\rho_{C}$. Preliminary studies suggest that eqn 2.4 also tends to hold for strong selection. The basic idea is that natural selection on graphs (in structured populations) can favor unconditional cooperation without any need for strategic complexity, reputation, or kin selection.

Games on graphs grew out of the earlier tradition of spatial evolutionary game theory (Nowak and May, 1992; Herz, 1994; Killingback and Doebeli, 1996; Mitteldorf and Wilson, 2000; Hauert et al., 2002; Le Galliard et al., 2003; Hauert and Doebeli, 2004; Szabo' and Vukov, 2004) and investigations of spatial models in ecology (Durrett and Levin, 1994a, 1994b; Hassell et al., 1994; Tilman and Kareiva, 1997; Neuhauser, 2001) and spatial models in population genetics (Wright, 1931; Fisher and Ford, 1950; Maruyama, 1970; Slatkin, 1981; Barton, 1993; Pulliam, 1988; Whitlock, 2003).

\subsection{Group selection}

The enthusiastic approach of early group selectionists to explain all evolution of cooperation from this one perspective (Wynne-Edwards, 1962) has met with vigorous criticism (Williams, 1966) and even a denial of group selection for decades. Only an embattled minority of scientists defended the approach (Eshel, 1972; Wilson, 1975; Matessi and Jayakar, 1976; Wade, 1976; Uyenoyama and Feldman, 1980; Slatkin, 1981; Leigh, 1983; Szathmary and Demeter, 1987). Nowadays it seems clear that group 
selection can be a powerful mechanism to promote cooperation (Sober and Wilson, 1998; Keller, 1999; Michod, 1999; Swenson et al., 2000; Kerr and Godfrey-Smith, 2002; Paulsson, 2002; Boyd and Richerson, 2002; Bowles and Gintis, 2004; Traulsen et al., 2005). We only have to make sure that its basic requirements are fulfilled in a particular situation (Maynard Smith, 1976). Exactly what these requirements are can be illustrated with a simple model (Traulsen and Nowak, 2006).

Imagine a population of individuals subdivided into groups. For simplicity, we assume that the number of groups is constant and given by $m$. Each group contains between 1 and $n$ individuals. The total population size can fluctuate between the bounds $\mathrm{m}$ and $\mathrm{nm}$. Again, there are two types of individual, cooperators and defectors. Individuals interact with others in their group and thereby receive a payoff. At each time step a random individual from the entire population is chosen proportional to payoff in order to reproduce. The offspring is added to the same group. If the group size is less than or equal to $\mathrm{n}$ then nothing else happens. If the group size, however, exceeds $\mathrm{n}$ then with probability $q$ the group splits into two. In this case, a random group is eliminated (in order to maintain a constant number of groups). With probability $1-q$, the group does not divide, but instead a random individual from that group is eliminated (Figure 2.6).

This minimalist model of multilevel selection has some interesting features. Note that the evolutionary dynamics are entirely driven by individual fitness. Only individuals are assigned payoff values. Only individuals reproduce. Groups can stay together or split (divide) when reaching a certain size. Groups that contain fitter individuals reach the critical size faster and therefore split more often. This concept leads to selection among groups, although only individuals reproduce. The higher level selection emerges from lower level reproduction. Remarkably, the two levels of selection can oppose each other.

As before, we can compute the fixation probabilities, $\rho_{C}$ and $\rho_{D}$, of cooperators and defectors to check whether selection favors one or the other. If we add a single cooperator to a population of defectors, then this cooperator must first take over a group. Subsequently the group of cooperators must take over the entire population. The first step is opposed by selection, the second step is favored by selection. Hence, we need to find out if the overall fixation probability is greater to or less than what we would obtain for a neutral mutant. An analytic calculation is possible in the interesting limit $q \ll 1$, where individuals reproduce much more rapidly than groups divide. In this case, most of the groups are at their maximum size and hence the total population size is almost constant and given by $N=n m$. We find that selection favors cooperators and opposes defectors, $\rho_{C}>1 / N>\rho_{D}$, if

$b / c>1+n /(m-2)$

This result holds for weak selection. Smaller group sizes and larger numbers of competing groups favor cooperation. We also notice that the number of groups, $m$, must exceed 2. There is an intuitive reason for this threshold. Consider the case of $m=2$ groups with $n=2$ individuals. In a mixed group, the cooperator has payoff $-c$ and the defector has payoff $b$; the defector/cooperator difference is $b+c$. In a homogeneous 
group, two cooperators have payoff $b-c$, while two defectors have a payoff of 0 . Thus the disadvantage for cooperators in mixed groups cannot be compensated for by the advantage they have in homogeneous groups. Interestingly, however, for larger splitting probabilities, $q$, we find that cooperators can be favored even for $m=2$ groups. The reason is the following: for very small $q$, the initial cooperator must reach fixation in a mixed group; but for larger $q$, a homogeneous cooperator group can also emerge if a mixed group splits, giving rise to a daughter group that has only cooperators. Thus, larger splitting probabilities make it easier for cooperation to emerge.

Let us also consider the effect of migration between groups. The average number of migrants accepted by a group during its lifetime is denoted by $z$. We find that selection favors cooperation provided that

$b / c>1+z+n / m$

In order to derive this condition we have assumed weak selection and $q \ll 1$, as before, but also that both the numbers of groups, $m$, and the maximum group size, $n$, are much larger than 1.

Group selection (or multilevel selection) is a powerful mechanism for the evolution of cooperation if there is a large number of relatively small groups and migration between groups is not too frequent.

\subsection{Conclusion}

We end by listing the five rules that we mentioned in the beginning. These rules represent laws of nature governing the natural selection of cooperation.

1. Kin selection leads to cooperation if $b / c>1 / r$, where $r$ is the coefficient of genetic relatedness between donor and recipient.

2. Direct reciprocity leads to cooperation if $b / c>1 / w$, where $w$ is the probability of playing another round in the repeated Prisoner's Dilemma.

3. Indirect reciprocity leads to cooperation if $b / c>1 / q$, where $q$ is the probability of knowing the reputation of a recipient.

4. Graph selection (or network reciprocity) leads to cooperation if $b / c>k$, where $k$ is the degree of the graph; that is, the average number of neighbors.

5. Group selection leads to cooperation if $b / c>1+z+n / m$, where $z$ is the number of migrants accepted by a group during its lifetime, $n$ is the group size, and $m$ is the number of groups.

In all five theories, $b$ is the benefit for the recipient and $c$ the cost for the donor of an altruistic act. 


\section{References}

Abramson, G. and Kuperman, M. 2001. Social games in a social network. Physical Review E 63: 030901R (1-4).

Axelrod, R. and Hamilton, W.D.1981.The evolution of cooperation. Science 211: 13901396.

Axelrod, R.M. 1984. The Evolution of Cooperation. Basic Books, New York.

Barton, N. 1993. The probability of fixation of a favoured allele in a subdivided population. Genetic Research 62: 149-158.

Bowles, S. and Gintis, H. 2004. The evolution of strong reciprocity: cooperation in heterogeneous populations. Theoretical Population Biology 65: 17-28.

Boyd, R. and Richerson, P.J. 2002. Group beneficial norms can spread rapidly in a structured population. Journal of Theoretical Biology 215: 287-296.

Brandt, H. and Sigmund, K. 2004. The logic of reprobation: assessment and action rules for indirect reciprocity. Journal of Theoretical Biology 231: 475-486.

Brandt, H. and Sigmund, K. 2005. Indirect reciprocity, image scoring, and moral hazard. Proceedings of the National Academy of Sciences USA 102: 2666-2670.

Ebel, H. and Bornholdt, S. 2002. Coevolutionary games on networks. Physical Review E66: 056118 (1-8).

Eshel, I. 1972. Neighbor effect and the evolution of altruistic traits. Theoretical Population Biology 3: 258-277.

Fehr, E. and Fischbacher, U. 2003. The nature of human altruism. Nature 425: 785-791.

Fehr, E. and Gachter, S. 2002. Altruistic punishment in humans. Nature 415: 137-140.

Fisher, R.A. and Ford, E.B. 1950. The Sewall Wright effect. Heredity 4: 117-119.

Fishman, M.A. 2003. Indirect reciprocity among imperfect individuals. Journal of Theoretical Biology 225: 285-292.

Frank, S.A. 1998. Foundations of Social Evolution. Princeton University Press, Princeton, NJ.

Fudenberg, D. and Maskin, E. 1990. Evolution and cooperation in noisy repeated games. American Economics Review 80: 274-279.

Hamilton, W.D. 1964a. The genetical evolution of social behaviour I. Journal of Theoretical Biology 7: 1-16.

Hamilton, W.D. 1964b. The genetical evolution of social behaviour II. Journal of Theoretical Biology 7: 17-52.

Hamilton, W.D. 1998. Narrow Roads of Gene Land: the Collected Papers of W.D. Hamilton, Volume 1: Evolution of Social Behaviour. Oxford University Press, New York. 
Hassell, M.P., Comins, H.N., and May, R.M. 1994. Species coexistence and selforganizing spatial dynamics. Nature 370: 290-292.

Hauert, C. and Doebeli, M. 2004. Spatial structure often inhibits the evolution of cooperation in the snowdrift game. Nature 428: 643-646.

Hauert, C., DeMonte, S., Hofbauer, J. and Sigmund, K. 2002. Volunteering as red queen mechanism for cooperation in public goods games. Science 296: 1129-1132.

Herz, A.V.M. 1994. Collective phenomena in spatially extended evolutionary games. Journal of Theoretical Biology 169: 65-87.

Hofbauer, J. and Sigmund, K. 1998. Evolutionary Games and Population Dynamics. Cambridge University Press, Cambridge.

Keller, L. (ed.) 1999. Levels of Selection in Evolution. Princeton University Press, Princeton, NJ.

Kerr, B. and Godfrey-Smith, P. 2002. Individualist and multi-level perspectives on selection in structured populations. Biology \& Philosophy 17: 477-517.

Killingback, T. and Doebeli, M. 1996. Spatial evolutionary game theory: Hawks and Doves revisited. Proceedings of the Royal Society of London Series B Biological Sciences 263: 1135-1144.

Krebs, J.R. and Davies, N.B. (eds) 1997. Behavioral Ecology: an Evolutionary Approach, $4^{\text {th }}$ edn. Blackwell Science, Malden, MA.

Le Galliardt, J.-F., Ferriere, R., and Dieckmann, U. 2003. The adaptive dynamics of altruism in spatially heterogeneous populations. Evolution 57: 1-17.

Leigh, E.G., 1983. When does the good of the group override the advantage of the individual? Proceedings of the National Academy of Sciences USA 80: 2985-2989.

Leimar, O. and Hammerstein, P. 2001. Evolution of cooperation through indirect reciprocation. Proceedings of the Royal Society of London Series B Biological Sciences 268: 745-753.

Lieberman, E., Hauert, C, and Nowak, M.A. 2005. Evolutionary dynamics on graphs. Nature 433: 312-316.

Luce, R.D. and Riaffa, H. 1957. Games and Decisions. John Wiley, New York.

Maruyama, T. 1970. Effective number of alleles in a subdivided population. Theoretical Population Biology 1: 273-306.

Matessi, C. and Jayakar, S.D. 1976. Conditions for the evolution of altruism under Darwinian selection. Theoretical Population Biology 9: 360-387.

May, R.M. 1987. More evolution of cooperation. Nature 327: 15-17.

Maynard Smith, J. 1964. Group selection and kin selection. Nature 63: 20-29.

Maynard Smith, J. 1976. Group selection. Quarterly Review of Biology 201: 145-147.

Michod, R.E. 1999. Darwinian Dynamics: Evolutionary Transitions in Fitness and Individuality. Princeton University Press, Princeton, NJ. 
Milinski, M., Semmann, D., and Krambeck, H.-J. 2002. Reputation helps solve the 'tragedy of the commons'. Nature 415: 424-426.

Milinski, M., Semmann, D., Bakker, T.C.M., and Krambeck, H.-J. 2001. Cooperation through indirect reciprocity: image scoring or standing strategy? Proceedings of the Royal Society of London Series B Biological Sciences 268: 2495-2501.

Mitteldorf, J. and Wilson, D.S. 2000. Population viscosity and the evolution of altruism. Journal of Theoretical Biology 204: 481-496.

Molander, P. 1985. The optimal level of generosity in a selfish, uncertain environment. Journal of Conflict Resolution 29: 611-618.

Nakamaru, M. and Iwasa, Y. 2005. The evolution of altruism by costly punishment in lattice-structured populations: Score-dependent viability versus score-dependent fertility. Evolutionary Ecology Research 7: 853-870.

Nakamaru, M., Matsuda, H., and Iwasa, Y. 1997. The evolution of cooperation in a lattice-structured population. Journal of Theoretical Biology 184: 65-81.

Nakamaru, M., Nogami, H., and Iwasa, Y. 1998. Score-dependent fertility model for the evolution of cooperation in a lattice. Journal of Theoretical Biology 194: 101-124.

Neuhauser, C. 2001. Mathematical challenges in spatial ecology. North American Mathematical Society 48: 1304-1314.

Nowak, M. and Sigmund, K. 1993. A strategy of win-stay, lose-shift that outperforms titfor-tat in the prisoner's dilemma game. Nature 364: 56-58.

Nowak, M.A and May, R.M. 1992. Evolutionary games and spatial chaos. Nature 359: 826-829.

Nowak, M.A and Sigmund, K. 1998a. Evolution of indirect reciprocity by image scoring. Nature 393: 573-577.

Nowak, M.A and Sigmund, K. 1998b. The dynamics of indirect reciprocity. Journal of Theoretical Biology 194: 561-574.

Nowak, M.A and Sigmund, K. 2005. Evolution of indirect reciprocity. Nature 437: 12911298.

Nowak, M.A. and May, R.M. 1992. Evolutionary games and spatial chaos. Nature 359: 826-829.

Ohtsuki, H. and Iwasa, Y. 2004. How should we define goodness? Reputation dynamics in indirect reciprocity. Journal of Theoretical Biology 231: 107-120.

Ohtsuki, H. and Iwasa, Y. 2005. The leading eight: social norms that can maintain cooperation by indirect reciprocity. Journal of Theoretical Biology 239: 435-444.

Ohtsuki, H., Hauert, C., Lieberman, E., and Nowak, M.A. 2006. A simple rule for the evolution of cooperation on graphs. Nature 441: 502-505.

Panchanathan, K. and Boyd, R. 2003. A tale of two defectors: the importance of standing for evolution of indirect reciprocity. Journal of Theoretical Biology 224: 115-126.

Paulsson, J. 2002. Multileveled selection on plasmid replication. Genetics 161: 13731384. 
Pulliam, H.R. 1988. Sources, sinks, and population regulation. American Naturalist 132: 652-661.

Rapoport, A. and Chammah, A.M. 1965. Prisoner's Dilemma. University of Michigan Press, Ann Arbor, MI.

Santos, F.C. and Pacheco, J.M. 2005. Scale-free networks provide a unifying framework for the emergence of cooperation. Physical Review Letters 95: 98104-1-98104-4.

Santos, F.C., Rodrigues, J.F., and Pacheco, J.M. 2005. Graph topology plays a determinant role in the evolution of cooperation. Proceedings of the Royal Society of London Series B Biological Sciences 273: 51-55.

Seinen, I. and Schram, A. 2006. Social status and group norms: indirect reciprocity in a repeated helping experiment. European Economics Review 50: 581-602.

Skyrms, B. and Pemantle, K 2000. A dynamic model of social network formation. Proceedings of the National Academy of Sciences USA 97: 9340-9346.

Slatkin, M. 1981. Fixation probabilities and fixation times in a subdivided population. Evolution 35: 477-488.

Sober, E. and Wilson, D.S. 1998. Unto Others: the Evolution and Psychology of Unselfish Behavior. Harvard University Press, Cambridge, MA.

Sugden, R. 1986. The Economics of Rights, Co-operation and Welfare. Blackwell Scientific Publications, Oxford.

Swenson, W., Wilson, D.S., and Elias, R. 2000. Artificial ecosystem selection. Proceedings of the National Academy of Sciences USA 97: 9110-9114.

Szabo, G. and Vukov, J. 2004. Cooperation for volunteering and partially random partnerships. Physical Review E 69: 0361070-7.

Szathmary, E. and Demeter, L. 1987. Group selection of early replicators and the origin of life. Journal of Theoretical Biology 128: 463-486.

Takahashi, N. and Mashima, R. 2003. The Emergence of Indirect Reciprocity: is the Standing Strategy the Answer?, Working Paper Series no. 29. Center for the Study of Cultural and Ecological Foundations of the Mind, Hokkaido University, Japan.

Taylor, PD. and Jonker, L.B. 1978. Evolutionary stable strategies and game dynamics. Mathematical Biosciences 40: 145-156.

Tilman, D. and Karieva, P. (eds) 1997. Spatial Ecology: the Role of Space in Population Dynamics and Interspecific Interactions, Monographs in Population Biology. Princeton University Press, Princeton, NJ.

Traulsen, A, Sengupta, A.M., and Nowak, M.A. 2005. Stochastic evolutionary dynamics on two levels. Journal of Theoretical Biology 235: 393-401.

Traulsen, A. and Nowak, M.A. 2006. Evolution of cooperation by multi-level selection. Proceedings of the National Academy of Sciences USA 103: 10952-10955.

Trivers, RL. 1971. The evolution of reciprocal altruism. Quarterly Review of Biology 46: 35-57. 
Uyenoyama, M. and Feldman, M.W. 1980. Theories of kin and group selection: a population genetics perspective. Theoretical Population Biology 17: 380-414.

Wade, M.J. 1976. Group selection among laboratory populations of Tribolium. Proceedings of the National Academy of Sciences USA 73: 4604-4607.

Wedekind, C. and Braithwaite, V.A. 2002. The long term benefits of human generosity in indirect reciprocity. Current Biology 12: 1012-1015.

Wedekind, C. and Milinski, M. 2000. Cooperation through image scoring in humans. Science 288: 850-852.

Whitlock, M. 2003. Fixation probability and time in subdivided populations. Genetics 164: 767-779.

Williams, G.C. 1966. Adaptation and Natural Selection. Princeton University Press, Princeton, NJ.

Wilson, E.O. 1975. Sociobiology. Harvard University Press, Cambridge, MA.

Wilson, E.O. and Hölldobler, B. 2005. Eusociality: origin and consequences. Proceedings of the National Academy of Sciences USA 102: 13367-13371.

Wright, S. 1931. Evolution in Mendelian populations. Genetics 16: 97-159.

Wynn-Edwards, V.C. 1962. Animal Dispersion in Relation to Social Behavior. Oliver and Boyd, London.

\section{Figures}

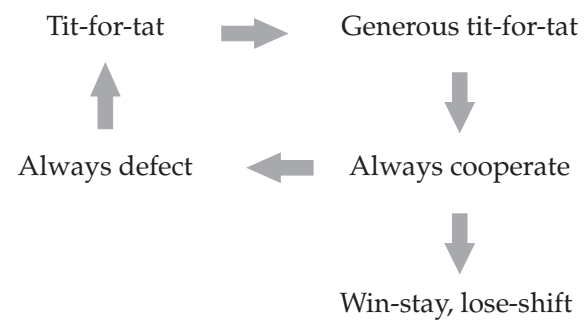

Figure 2.1 Evolutionary cycles of cooperation and defection. A small cluster of tit-for-tat (TFT) players or even a lineage starting from a single TFT player in a finite population can invade an always defect (ALLD) population. In fact, TFT is the most efficient catalyst for the first emergence of cooperation in an ALLD population. But in a world of fuzzy minds and trembling hands, TFT is soon replaced by generous tit-for-tat (GTFT), which can re-establish cooperation after occasional mistakes. If everybody uses GTFT, then always cooperate (ALLC) is a neutral variant. Random drift leads to ALLC. An ALLC population invites invasion by ALLD. But ALLC is also dominated by win-stay, lose-shift (WSLS), which leads to more stable cooperation than TFT-like strategies. 


$\begin{array}{ll}\text { Win-stay } & \\ \text { C (3) .... C } & \text { D (5) .... D } \\ \text { C } & \text { C } \\ \text { Lose-shift } & \\ \text { C (0) .... D } & \text { D (1) .... C (probabilistic) } \\ \text { D } & \text { D }\end{array}$

Figure 2.2 Win-stay, lose-shift (WSLS) embodies a very simple principle. If you do well then continue with what you are doing. If you are not doing well, then try something else. Here we consider the Prisoner's Dilemma payoff values $R=3, T=5, p=1$, and $S=0$. If both players cooperate, you receive three points, and you continue to cooperate. If you defect against a cooperator, you receive five points, and you continue to defect. But if you cooperate with a defector, you receive no points, and therefore you will switch from cooperation to defection. If, on the other hand, you defect against a defector, you receive one point, and you will switch to cooperation. Your aspiration level is three points. If you get at least three points then you consider it a win and you will stay with your current choice. If you get less than three points, you consider it a loss and you will shift to another move. If $R>(T+P) / 2$ (or $b / c>2$ ) then WSLS is stable against invasion by ALLD. If this inequality does not hold, then our evolutionary simulations lead to a stochastic variant of WSLS, which cooperates after a DD move only with a certain probability. This stochastic variant of WSLS is then stable against invasion by ALLD.

Reputation of donor and recipient

\begin{tabular}{c|cccc|}
\multicolumn{1}{c}{} & GG & GB & BG & \multicolumn{1}{l}{ BB } \\
\cline { 2 - 5 } C & G & G & G & G \\
D & B & B & B & B \\
\cline { 2 - 4 } & & & &
\end{tabular}

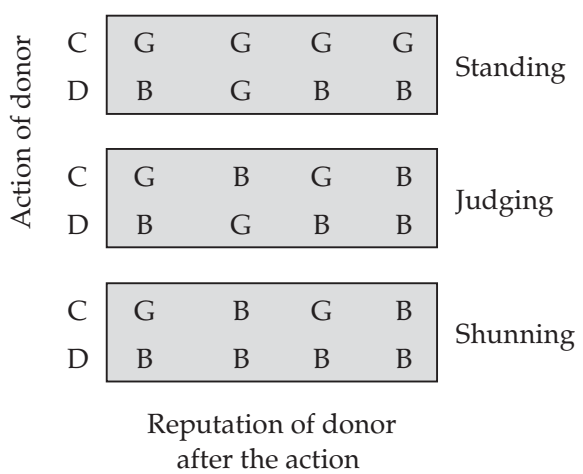

Figure 2.3 Four assessment rules. Assessment rules specify how an observer judges an interaction between a potential donor and a recipient. Here we show four examples of assessment rules in a world of binary reputation, good (G) and bad (B). For scoring, cooperation (C) earns a good reputation and defection (D) earns a bad reputation. Standing is very similar to scoring; the only difference is that a good donor can defect against a bad recipient without losing his good reputation. Note that scoring is associated with costly punishment (Sigmund et al., 2001; Fehr and Gaechter, 2002), whereas for standing punishment of bad recipients is cost-free. For judging it is bad to help a bad recipient. Shunning assigns a bad reputation to any donor who interacts with a bad recipient. 

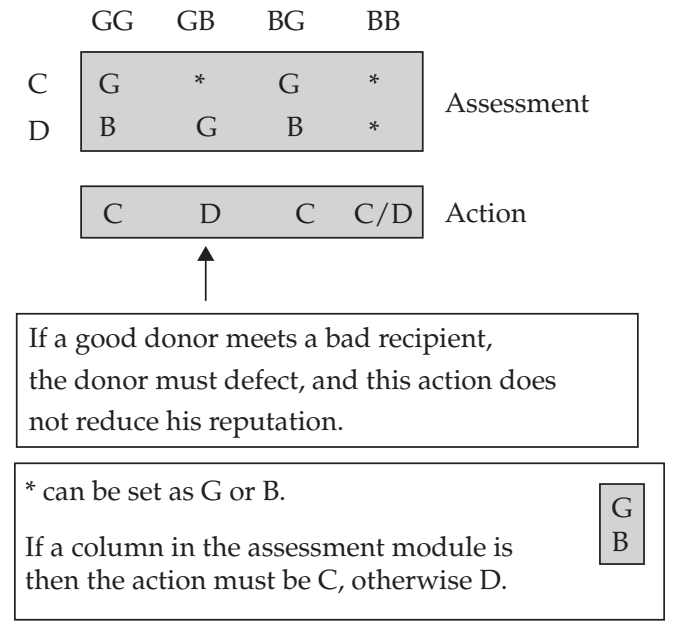

Figure 2.4 Ohtsuki and Iwasa's leading eight. Ohtsuki and Iwasa (2004, 2005) have analyzed the combination of $2^{8}=256$ assessment modules with $2^{4}=16$ action modules. This is a total of 4096 strategies. They have found that eight of these strategies can be evolutionarily stable and lead to cooperation, provided that everybody agrees on each other's reputation. (In general, uncertainty and incomplete information might lead to private lists of the reputation of others.) The three asterisks in the assessment module indicate a free choice between $\mathrm{G}$ and $\mathrm{B}$. There are therefore $2^{3}=8$ different assessment rules which make up the leading eight. The action module is built as follows: if the column in the assessment module is $\mathrm{G}$ and $\mathrm{B}$, then the corresponding action is $\mathrm{C}$, otherwise the action is D. Note that standing and judging are members of the leading eight, but that scoring and shunning are not.

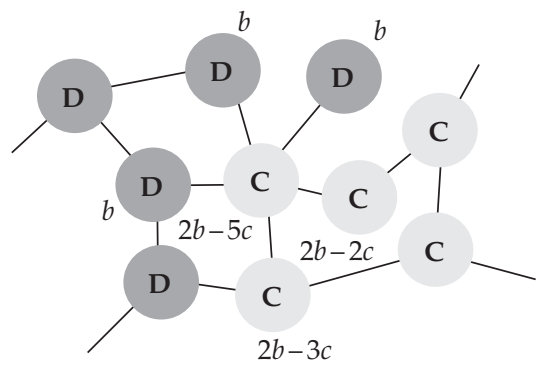

Figure 2.5 Games on graphs. The members of a population occupy the vertices of a graph (or social network). The edges denote who interacts with whom. Here we consider the specific example of cooperators, $C$, competing with defectors, $D$. A cooperator pays a cost, $c$, for every link. Each neighbor of a cooperator receives a benefit, $b$. The payoffs of some individuals are indicated in the figure. The fitness of each individual is a constant, denoting the baseline fitness, plus the payoff of the game. For evolutionary dynamics, we assume that in each round a random player is chosen to die, and the neighbors compete for the empty site proportional to their fitness. A simple rule emerges: if $b / c>k$ then selection favors cooperators over defectors. Here $k$ is the average number of neighbors per individual. 


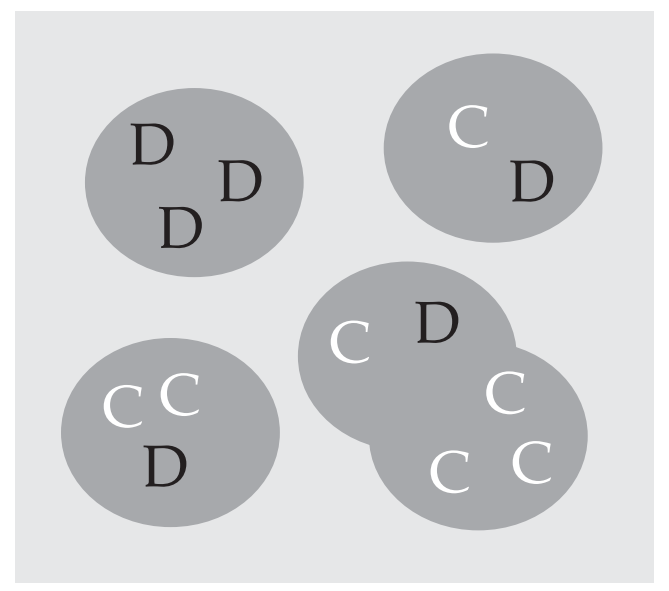

Figure 2.6 A simple model of group selection. A population consists of $m$ groups of maximum size $n$. Individuals interact with others in their group in the context of an evolutionary game. Here we consider the game between cooperators, $C$, and defectors, $D$. For reproduction, individuals are chosen from the entire population with a probability proportional to their payoff. The offspring is added to the same group. If a group reaches the maximum size, $n$, then it either splits in two or a random individual from that group is eliminated. If a group splits, then a random group dies, in order to keep the total population size constant. This metapopulation structure leads to the emergence of two levels of selection, although only individuals reproduce. 